\title{
Current Status and Challenges of Community-Based Elderly Care Centers in Chongqing, China: A Cross-Sectional Study
}

This article was published in the following Dove Press journal: Risk Management and Healthcare Policy

\author{
Ziyi Yang (D' \\ Yi Jiang ${ }^{2-4}$ \\ Min Wang ${ }^{5}$ \\ Huan Zeng ${ }^{2-4}$ \\ 'The First Clinical College, Chongqing \\ Medical University, Chongqing, People's \\ Republic of China; ${ }^{2}$ School of Public \\ Health and Management, Chongqing \\ Medical University, Chongqing, People's \\ Republic of China; ${ }^{3}$ Research Center for \\ Medicine and Social Development, \\ Chongqing Medical University, \\ Chongqing, People's Republic of China; \\ ${ }^{4}$ Innovation Center for Social Risk \\ Governance in Health, Chongqing \\ Medical University, Chongqing, People's \\ Republic of China; ${ }^{5}$ North Sichuan \\ Medical College, Nanchong, Sichuan, \\ People's Republic of China
}

Purpose: China is facing various societal pressures owing to its rapidly aging population. In order to provide evidence-based suggestions to promote elderly care, this study investigated the community-based elderly care centres (CBECCs) in Chongqing of China, focusing on the site selections, physical environment, facilities, and operation.

Methods: All CBECCs in a district of Chongqing were analysed via a single-stage cluster sampling survey design. Descriptive statistics were used to analyse the data.

Results: A total of 69 CBECCs (60 government-run and 9 collective-run centres) were identified and analysed. Most site selections were reasonable. CBECCs that were located inside of apartment complexes with entrance guards, not located on main roads, and near a market were more popular. Only 4 (13.3\%) CBECCs that were not located on the ground floor were equipped with elevators. A small number of CBECCs were near a noise pollution $(10.1 \%)$ or far from a medical institution $(11.6 \%)$. Nearly half $(42.7 \%)$ of CBECCs only had an indoor area of $<200 \mathrm{~m} 2$. Nearly all CBECCs had sufficient ventilation, natural lighting, and sufficient floor-to-floor height. $51.5 \%$ and $88.4 \%$ of the CBECCs fully met the criteria of 'four rooms and one canteen' and 'eight functional zones', but no significant difference was found in terms of the number of people served per month between the CBECCs that met the criteria and those that did not. A quarter of the CBECCs were operated by part-time staff. Only half provided home services $(54.5 \%)$. The median of average number of people they served every month was 100 (interquartile range $=10-300$ ).

Conclusion: Certain problems existed in the current CBECCs. Better elderly care especially calls for adequate elevator establishment, sufficient indoor and outdoor space, appropriate facilities and service, qualified managers and caregivers. A feasible and evidence-based plan to optimize the physical environment and facilities, functional layout and service provision is crucial to improve the CBECC service.

Keywords: community-based elderly care centre, site selection, physical environment, facilities, cross-sectional survey, China

\section{Introduction}

Called the home of the world's largest population of about 1.4 billion, China is facing a challenge of its aging population. Data from the National Bureau of Statistics of China showed that the number of people aged $\geq 65$ exceeded 176 million in 2019, accounting for approximately $12.6 \%$ of the nation's total population, and this yearly demographic rate of growth is $5.7 \% .^{1}$ It is predicted that by 2050 , about $26.9 \%$ of the total population would be aged $\geq 65$. $^{2,3}$ The change
Correspondence: Huan Zeng Postal Address: School of Public Health and Management, Chongqing Medical University, I Yixueyuan Road, Yuzhong District, Chongqing 400016, People's

Republic of China

$\mathrm{Tel} / \mathrm{Fax}+8623657 / 4388$

Email huanzeng@cqmu.edu.cn
Risk Management and Healthcare Policy 2020:13 2975-2983

mit your manuscript (c) (i) (5) 2020 Yang et al. This work is published and licensed by Dove Medical Press Limited. The full terms of this license are available at https://www.dovepress.com/terms.php C. you hereby accept the Terms. Non-commercial uses of the work are permitted without any further permission from Dove Medical Press Limited, provided the work is properly attributed. For permission for commercial use of this work, please see paragraphs 4.2 and 5 of our Terms (https://www.dovepress.com/terms.php). 
of the age structure, combined with the country's rapid economic development and reforms, have had a vast influence on the traditional family support system. ${ }^{4,5}$ In China, the elderly used to be cared for by the younger generation in the family, especially when they developed a severe disease and lost self-care ability. ${ }^{6}$ However, because of the family planning policy, a "4-2-1" family structure gradually formed. ${ }^{7}$ Along with low fertility, rural-tourban migration, expanding female employment, and changes in the Chinese filial piety culture, the tradition of three generations living under the same roof has steadily declined, and this traditional way of family caregiving has gradually collapsed. ${ }^{89}$ In the future, this situation will be exacerbated as fewer children will be available to care for their aging parents.

In response to these pressing issues, efforts to develop an elderly care system have received growing attention in China. There are nursing homes in the country, largely sponsored by the local and national government with contributions from some non-government organisations and private investors. ${ }^{10,11}$ Nursing homes mainly accept elderly people without children and have no other means of support, including those labelled as "Three No's" (no children, no relatives, and no homes). Those who are not part of the "Three No's" can also choose to live in a nursing home based on their will and financial capability, but because of high occupancy, there are few healthy elderlies living in nursing homes. ${ }^{12}$ Community-based elderly care centre (CBECC) is a relatively new concept and choice for healthy elderly in China. In the country, CBECCs are divided into three main types: governmentrun (constructed and operated by the government), collective-run (constructed by the government but operated by non-profit organisations) and private (constructed and operated by private companies, mainly real-estate developers). CBECCs differ from nursing homes, since the elderly who choose CBECCs could be taken care of in CBECCs during daytime and workdays but still live at home on weekend. ${ }^{13}$ They can have their own social lives while younger family members can go to work or school without worrying about them being left alone at home. CBECCs are warmly welcomed by many old people since they can enable the elderly to live in a familiar environment and maintain their social network. With an expanding aging population in China, the demand for CBECCs has increased remarkably.

Considering the CBECCs are still developing at an early stage in China, complaints about CBECCs were often reported. Dire lack of qualified workers at all levels, including direct caregivers, administrators, nursing and medical professionals, was the most common problem. ${ }^{14,15}$ However, little is known about the status of CBECC's site selection, physical environment, facilities, and operation. Actually, these factors are largely associated with the quality of service. A more complete understanding of the current status and challenges of CBECCs could contribute to a better design and operation for elderly care. Locating in Chongqing, the southwest of China, this study aimed to describe the current status and challenges about site selection, physical environment, facilities, and operation of CBECCs. The results of this study will improve our understanding of the CBECC care in Chinese cities and help to promote the development of elderly care services in China.

\section{Materials and Methods}

\section{Aims of the Study}

This study was designed and conducted to explore the CBECC's status and challenges on site selections, physical environment, facilities, and operation, in order to provide a more complete understanding about the community-based elder care service industry and promote its development.

\section{Setting}

This study was carried out in Chongqing, a megacity with a total population of over 30 million and one of the four municipalities under the direct administration of the Chinese central government. The number of people aged $\geq 60$ in Chongqing is over 7.19 million, accounting for $21.1 \%$ of the city's total population. ${ }^{1}$ The Chongqing government has promulgated policies to promote the development of CBECCs, and the most important policy is the Qianbai Project, which aims to build 1000 CBECCs and 100 municipal CBECC demonstrations in the city. ${ }^{16,17}$ The Qianbai Project requests that each CBECC should include "four rooms and one canteen"; the rooms are separately used for entertainment, reading, exercise, and day-care, whereas cooked meals are provided in the canteen. Moreover, the Project requires that each CBECC has 'eight functional zones'. These zones are designed to provide services related to reception, daily care (laundry, grocery delivery, and other housekeeping services), nursing (morning care, toileting, bathing, blood pressure and blood glucose measurement), health management (health guidance, rehabilitation, physiotherapy, medicine delivery, nutrition care, and hospice care), cultural and educational 
activities (music, dance, painting, and smartphone lessons for seniors), humanistic care (psychological counselling, mediation of disputes, and legal assistance), entertainment (chess, mah-jong, and square dance), and operational management. With regard to site selections and physical environment, the Project states that CBECCs should meet the following conditions: 1) have sufficient ventilation and natural lighting, away from pollution; 2) close to a medical institution, a community service centre, and other public facilities; 3 ) can be conveniently accessed via public transportation; 4) located on the ground floor with exclusive front doors (if cannot be established on the ground floor, a barrier-free elevator should be equipped); 5) and have a minimum indoor area of 200 square meters. If possible, they should also provide venues for outdoor activities.

\section{Study Design and Measurement}

This was a descriptive cross-sectional study. All CBECCs in a district of Chongqing were analysed using a single stage cluster sampling survey design. A questionnaire consisting of four parts was developed on the basis of reports in the literature, opinions from relevant field specialists, government documents, and related policies. ${ }^{16,17}$ The first part was used to collect the site selection details of CBECCs, including location, public transportation, and distance to a clinic. The second part focused on the physical environment, including total area, natural lighting and ventilation. The third part was designed to assess the operational status of "four rooms and one canteen" and the "eight functional zones". The fourth part was formulated to collect information on operation, including opening hours and number of people served every month.

\section{Data Collection and Statistical Analyses}

Permissions were obtained from the CBECCs prior to data collection. The data were collected by a survey team trained specifically for this study. Relevant authorities were contacted to obtain the address of each CBECC. The team members visited each CBECC and filled out questionnaires via on-site surveys and interviews. The data obtained were entered into an electronic database, and correctness of data transmission was checked twice by two independent researchers to ensure data validity and reliability. Two epidemiologists controlled the questionnaires and checked the administrative data. The survey was conducted from May 2018 to June 2018. For quantitative variables, median number (Mdn) and interquartile range (IQR) were used in the descriptive statistics. Chisquared test and Mann-Whitney U-test were used for nonparametric tests. All statistical analyses were performed using SPSS version 25 (SPSS Inc., Chicago, IL) and GraphPad Prism version 8.0.1 (GraphPad Software, La Jolla, CA).

\section{Ethical Approval}

The study was conducted in accordance with the Declaration of Helsinki. Ethical approval was obtained from the Ethics Committee of Chongqing Medical University.

\section{Results CBECC Site Selections}

A total of 69 CBECCs in 22 neighbourhoods were identified in this district, in which 9 were collective-run and 60 were government-run. As shown in Table 1, nearly three quarters $(72.5 \%, 50 / 69)$ were located outside of apartment complexes and nearly all could be entered without entrance guards. About sixty percent (59.4\%, 41/69) were located along main roads and a majority of them $(79.7 \%, 55 / 69)$ could be accessed via public transportation. Some CBECCs $(10.1 \%, 7 / 69)$ suffered from noise pollution. A small proportion was far away from a medical institution $(11.6 \%, 8 / 69)$. Figure 1 shows that about a half of these CBECCs were not located on the ground floor, and only 4 were equipped with elevators. The CBECCs located inside apartment complexes could not be accessed without entrance guards, not located along main roads, and near a market, store or a bazaar served more people per month than the others (p-values were 0.009, 0.016, 0.009, and 0.001 , respectively) (Table 1).

\section{Physical Environment of CBECCs}

Most of the CBECCs surveyed (82.6\%, 57/69) utilised community office buildings, whereas the remaining CBECCs $(11.6 \%, 12 / 69)$ were rented. The proportions of indoor areas $<200,200-750$, and $>750 \mathrm{~m}^{2}$ were $42.7 \%$ (29/69), $51.4 \%(36 / 69)$ and $5.9 \%(4 / 69)$, respectively. The scatter plot for each CBECC is shown in Figure 2. Over half of the CBECCs had an exclusive front door $(68.1 \%, 47 / 69)$ and sufficient natural lighting $(79.7 \%, 55 / 69)$. Nearly all CBECCs had sufficient ventilation $(88.4 \%, 61 / 69)$, windows $(97.1 \%, 67 / 69)$, and adequate floor-to-floor height $(92.8 \%$, 64/69). The Mdn of total area was 520.0 (IQR: 292.5-842.5) square meters. No difference in terms of area $(p=0.123$, 
Table I Site Selection Details of CBECCs

\begin{tabular}{|c|c|c|c|}
\hline Characteristics & $\mathbf{N}(\%)$ & People Served per Month (Mdn) & $p$ \\
\hline Located outside of apartment complexes & & & 0.009 \\
\hline No & $19(27.54)$ & 180 & \\
\hline Yes & $50(72.46)$ & 65 & \\
\hline Can be accessed without entrance guards & & & 0.016 \\
\hline No & $5(7.20)$ & 160 & \\
\hline Yes & $64(92.80)$ & 75 & \\
\hline Located on main road & & & 0.009 \\
\hline No & $28(40.58)$ & 200 & \\
\hline Yes & $4 \mid(59.42)$ & 30 & \\
\hline \multicolumn{4}{|l|}{ Nearby noise pollution } \\
\hline No & $62(89.87)$ & 100 & 0.429 \\
\hline Yes & $7(10.13)$ & 47.5 & \\
\hline Distance to a medical institution & & & 0.993 \\
\hline$<500 \mathrm{~m}$ & $6 I(88.4 I)$ & 100 & \\
\hline$\geq 500 \mathrm{~m}$ & 8 (II.59) & 85 & \\
\hline Public transportation & & & 0.377 \\
\hline None & $14(20.29)$ & 82.5 & \\
\hline Subway or bus & $55(79.7 I)$ & 100 & \\
\hline Near an outdoor activity venue & & & 0.093 \\
\hline No & $46(66.67)$ & 75 & \\
\hline Yes & $23(33.33)$ & 200 & \\
\hline Near a market, convenience store, or bazaar & & & 0.001 \\
\hline No & $21(30.43)$ & 15 & \\
\hline Yes & $48(69.57)$ & 120 & \\
\hline
\end{tabular}

0.089 , and 0.775 for total area, outdoor area, and indoor area, respectively) was observed between the collective-run and the government-run CBECCs. The CBECCs that met the government requirement for housing area (ie, had an indoor area of at least $\left.200 \mathrm{~m}^{2}\right)$ significantly $(\mathrm{p}=0.001)$ served more people $(\mathrm{Mdn}=140)$ than those $\operatorname{did} \operatorname{not}(\mathrm{Mdn}=15)$.

\section{Space Distribution: The "Four Rooms and One Canteen"}

Of the 69 CBECCs surveyed, about half $(51.5 \%, 36 / 69)$ fully met the criteria of "four rooms and one canteen". The pie chart for the number of rooms in a CBECC is shown in Figure 3. No significant difference in terms of the number of rooms was observed between the collective-run and the government-run CBECCs $(p=0.605)$. The proportions of CBECCs that had a day-care room, an entertainment room, a reading room, an exercise room, and a canteen were $72.5 \%$ (50/69), 88.4\% (61/ 69), 79.7\% (55/69), 81.2\% (56/69) and 53.6\% (37/69), respectively. Most people used the entertainment rooms more often than the other rooms $(\mathrm{Mdn}=70.0, \mathrm{IQR}=22.5-200.0)$. The number of people who utilised the other rooms was relatively low, especially the canteens $(30.4 \%, 21 / 69)$, which served an average of $<10$ people every month (Figure 3 ). When comparing the CBECCs that fully met the criteria of "Four rooms and one canteen" versus CBECCs that did not meet, no difference was found in the number of people served per month $(p=0.656)$.

\section{Setting of the "Eight Functional Zones"}

The functional zones used for entertainment $(89.9 \%, 62 / 69)$, operational management $(89.9 \%, 62 / 69)$, and cultural activities $(81.2 \%, 56 / 69)$ were common. However, nursing zones only existed in $27.5 \%(19 / 69)$ of all the CBECCs. A majority of the CBECCs $(88.4 \%, 61 / 69)$ met the criteria (ie, had at least four zones), but $21.7 \%$ (15/69) had four or fewer functional zones. No significant difference was found in terms of the number of people served per month between the CBECCs that met the criteria and those that did not $(\mathrm{p}=0.463)$. 


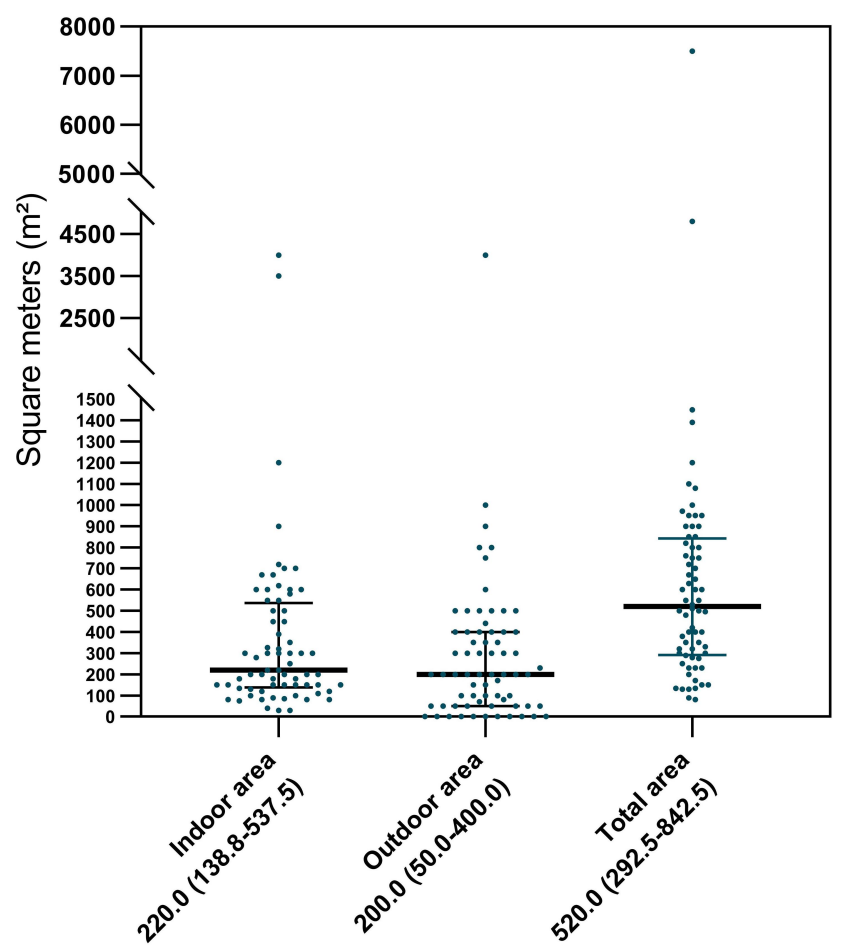

Figure I Details of floor distribution and barrier-free elevators of the CBECCs.
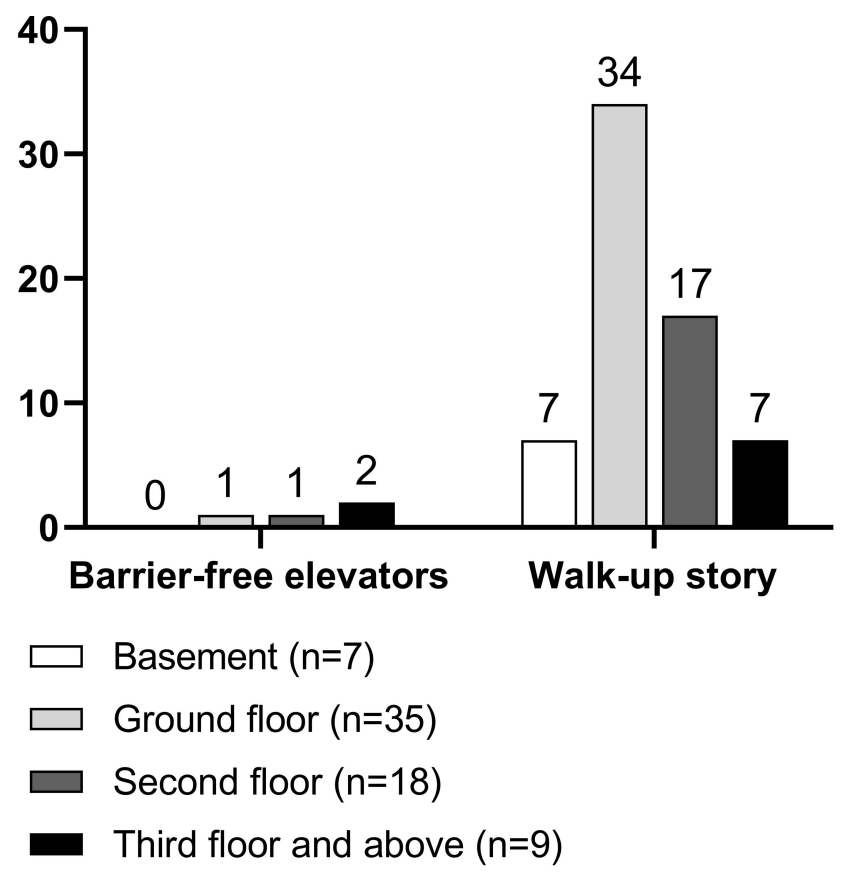

Figure 2 Scatter dot plot for the area of CBECCs.

\section{Operation of the CBECCs}

Among the 69 CBECCs, three halted operation due to several reasons. The average number of people they served per month ranged from 5 to 4200 . About three quarters of them had full-time staff $(74.2 \%, 49 / 66)$. The majority
$(75.8 \%, 50 / 66)$ were open on weekends, and nearly a half $(54.5 \%, 36 / 66)$ provided home services (ie, inhome services, such as personal hygiene, dressing, feeding, and taking medications) (Table 2). The business hours of most CBECCs were from 8 a.m. to 6 p.m., and only $6.0 \%(4 / 66)$ were around the clock. The most popular daily activities were health examination, watching television, playing mah-jong and chess, singing, and square dancing. The Mdn of average number of people they served every month was 100 (IQR $=10-300$ ) (Figure 4). The CBECCs that had full-time staff, provided home services, and opened around the clock served more people per month than those who did not have these features (p-values were $0.027,0.001$ and 0.007 , respectively) (Table 2). The collective-run CBECCs served significantly more people every month $(\mathrm{Mdn}=800)$ than the government-run CBECCs $(\mathrm{Mdn}=55)(\mathrm{p}=0.001)$.

\section{Discussion}

Aging has become a global issue in recent decades. Qualified elderly care facilities and services are pressing concerns for policymakers. ${ }^{18-20}$ A large number of studies highlight the importance of good-quality elderly care provided by CBECCs. ${ }^{21-23}$ Unlike other studies to analyze human resource or user's characteristics, ${ }^{20,24}$ the present study mainly focused on CBECC site selections, physical environment, facilities, and operation. After the investigation with 69 CBECCs in a district of Chongqing, China, this study provides a comprehensive understanding about the current status of the CBECCs, which would be essential to formulate effective elderly care strategies.

The site selections were mostly reasonable as nearly all the CBECCs could be conveniently reached via public transportation. However, the following two problems need to be considered for better services. Firstly, this study revealed that only very few CBECCs located on higher floors were equipped with elevators, making the visits inconvenient for those with disabilities. Recently, the government has issued a document to encourage elevator establishment in residential buildings to deal with aging problem. ${ }^{25}$ The CBECCs should catch this chance to install elevators. Secondly, several CBECCs faced severe noise pollution which should not be ignored. Moreover, some CBECCs were far away from a medical institution. Although the government only requires CBECCs to be close to a medical institution and sets no limit on distance, ${ }^{26}$ the lack of proximity to a medical institution may influence the availability of emergency service. Studies 


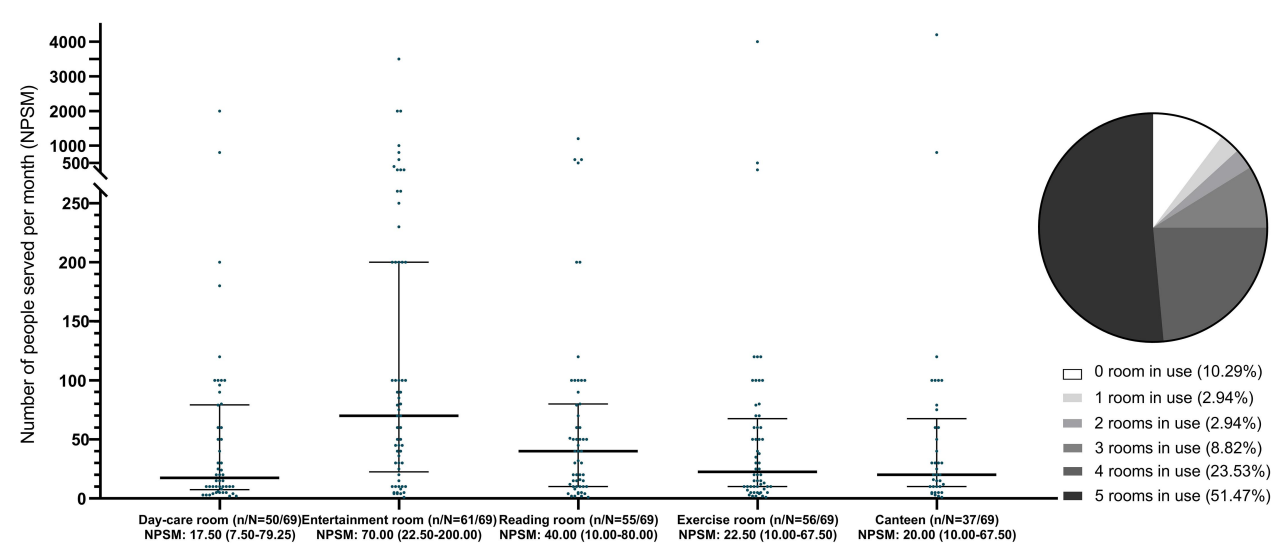

Figure 3 Operational details of "Four rooms and one canteen" of the CBECCs.

have showed that increased journey distance to a hospital appears to be associated with an increased risk of mortality in life-threatening conditions. ${ }^{27}$

With regard to physical environment, nearly all CBECCs had sufficient natural lighting, ventilation, windows, and adequate floor-to-floor height, indicating that they met the basic requirements set by the government. However, about half of the CBECCs (42.7\%) only had an indoor area of $<200 \mathrm{~m}^{2}$, which did not reach the government standards. Results showed that the CBECCs with larger indoor areas were more popular among the elderly, illustrating the importance of sufficient indoor area. Moreover, some CBECCs did not have venues for outdoor activities. This may restrict the elderly's participation in outdoor activities or exercises, such as square dancing (which is the most popular outdoor aerobic exercise among elderly Chinese) and Tai Chi. Governments of other cities or counties have imposed more detailed regulations on CBECC physical environment. For instance, every room used for habitation, office, or kitchen shall be provided with adequate natural lightning and ventilation in Hong Kong. ${ }^{28}$ In New York, there are specific standards for CBECC operable windows for ventilation and a minimum indoor area based on the number of beds. ${ }^{29}$ These specific and detailed specifications could help to generate a safer and more comfortable physical environment for the elderly.

In terms of the functional layout and facilities, results showed that $51.5 \%$ and $88.4 \%$ of the CBECCs fully met the criteria of "four rooms and one canteen" and "eight functional zones', indicating that over half of them followed the government's policies and requirements. Notably, a dire lack of nursing zone has been found in the statistic of the eight functional zones, which might be the result of the lack of professional nursing staff. Interestingly, no difference in terms of the number of people served every month was observed between the CBECCs that met these requirements and those that did not. This observation raises doubts as to

Table 2 Details of Service Provision

\begin{tabular}{|l|l|l|l|}
\hline Characteristics & N (\%) & People Served per Month (Mdn) & P \\
\hline $\begin{array}{l}\text { Have full-time staff } \\
\text { No }\end{array}$ & $17(25.8)$ & 17.5 & 0.027 \\
Yes & $49(74.2)$ & 105 & \\
\hline $\begin{array}{l}\text { Open on weekends } \\
\text { No }\end{array}$ & $16(24.3)$ & 100 & 0.813 \\
Yes & $50(75.8)$ & 77.5 & \\
\hline $\begin{array}{l}\text { Provide home services } \\
\text { No }\end{array}$ & $30(45.5)$ & 12.5 & 120 \\
Yes & $36(54.5)$ & 8.001 \\
\hline $\begin{array}{l}\text { Open 24-hours } \\
\text { No }\end{array}$ & $62(94.0)$ & 80 & 0.007 \\
Yes & $4(6.0)$ & 850 & \\
\hline
\end{tabular}




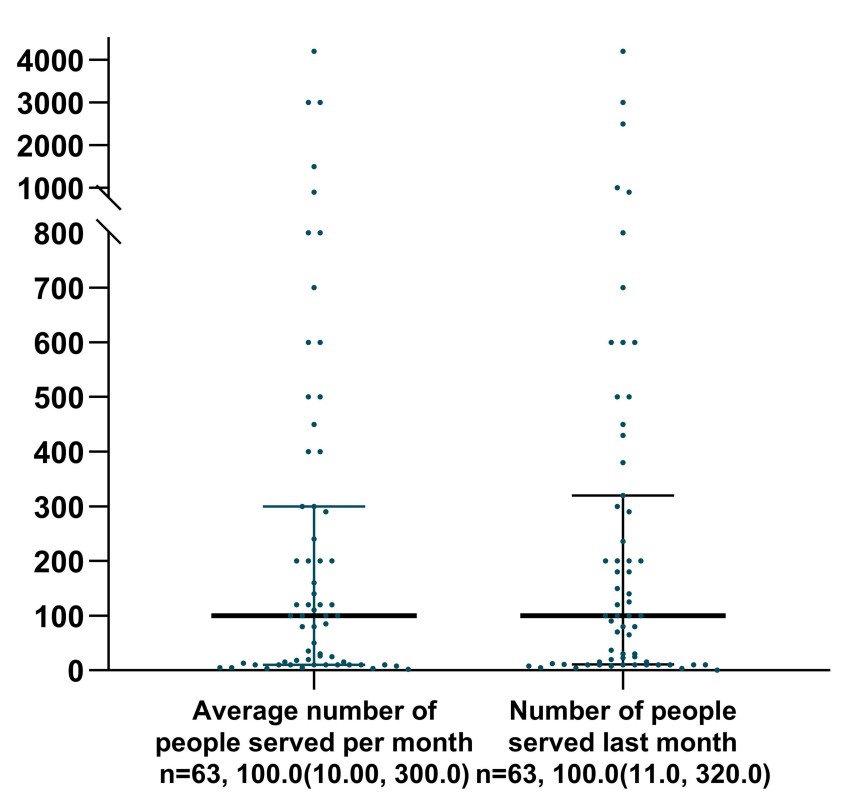

Figure 4 Scatter dot plot for the number of people served in the CBECCs.

whether these government policies and requirements truly fulfil the needs of the elderly. Most of the CBECCs provided services primarily based on the "four rooms and one canteen". However, about $30.7 \%$ of the CBECCs served $<10$ people every month. These findings suggest that specific studies are needed to fully understand the demand of the elderly and make sure the design of CBECCs' interior spatial and functional layout is welcomed by the elderly.

Our study also suggested that the number of people the CBECCs served every month was relatively very low. This may result from many factors. Firstly, certain CBECCs were managed by part-time workers, and some of them even had no professional qualifications. Secondly, the CBECCs were short of health professionals, thus health care services such as nursing, mental health care, and rehabilitation were not available. Studies have illustrated that CBECCs with adequate health professionals could provide good-quality elderly care, and it is suggested that the availability of professional caregivers is associated with increased residents' satisfaction. ${ }^{30,31}$ Thirdly, only a few of the CBECCs provided home services, while we found that CBECCs which could provide home services were more popular than those could not. For the elderly with disabilities, home services are essential to help improve their quality of life. ${ }^{23}$ Home services in Japan are mainly provided by professional nurses, thus making it possible to provide a more comprehensive and specialised care. ${ }^{32}$ However, shortage of caregiver is a big challenge worldwide. Various technologies (including robotics and telehealth) have been widely used to substitute, supplement, or simply support human caregivers in the delivery of elderly care in many countries, such as Japan, the USA, and some European countries. ${ }^{33,34}$ The expanding aging population and limited elderly care indicate that China has a long way to go to deal with the aging society effectively.

The present study has several limitations. First, it used a single-stage cluster sampling method, which may cause sampling error. Second, the CBECCs surveyed herein were all located in urban settings, it could not reflect the problems in rural areas. Third, this study focused largely on CBECC's site selections, physical environment, facilities, and operation. Further research is needed to evaluate the service quality of the CBECCs in more detail, as well as the physical characteristics of the users (eg, the elderly's age, presence of chronic disease, cognitive function and self-care ability). Such studies could provide important evidence to substantially improve the elderly care for China in the future.

\section{Conclusions}

Though the Chinese government has taken substantial actions to develop CBECCs, multiple problems of CBECCs in Chongqing have been identified by this study. This related to elevator establishment, sufficient indoor and outdoor space, appropriate facilities and service, qualified managers and caregivers. A feasible plan to optimize the physical environment and facilities, functional layout and service provision is crucial to improve the CBECC's service. Most importantly, the plan should be evidence-based and keeping a good balance between the government will, the user's taste and findings from studies.

\section{Abbreviations}

CBECC, community-based elderly care centre; Mdn, median number; IQR, interquartile range.

\section{Ethics Statement}

All participants were carefully informed about the protocol and provided written informed consent before inclusion in the study. The study was approved by the Ethics Committee of Chongqing Medical University.

\section{Funding}

This study is supported by Xintu Community Health Promotion Centre of Shanghai, China. The program is 
named "Capacity building strategy for community health promotion volunteers" (No. C19).

\section{Disclosure}

The authors declare no conflicts of interest.

\section{References}

1. National bureau of statistics of China. Available from: http://data. stats.gov.cn/index.htm/. Accessed August 2, 2020.

2. Zeng Y. Towards deeper research and better policy for healthy aging - using the unique data of chinese longitudinal healthy longevity survey. China Economic J. 2012;5:131-149. doi:10.1080/ 17538963.2013.764677

3. Wong Y, Leung J. Long-term care in China: issues and prospects. J Gerontol Soc Work. 2012;7:570-586.

4. Wu B, Carter M, Goins R, et al. Emerging services for communitybased long-term care in urban China: a systematic analysis of Shanghai's community-based agencies. $J$ Aging Soc Policy. 2005; 17:37-60. doi:10.1300/J031v17n04_03

5. Ma S, Shi J, Li L. Dilemmas in caring for older adults in Zhejiang Province, China: a qualitative study. BMC Public Health. 2019;19:311.

6. Sun S, Zheng H, Zhang L. Population ageing and nursing present conditions and countermeasures in China. $J$ Nursing Sci. 2006;21:76-79.

7. Jiang Q, Sánchez-Barricarte JJ. The 4-2-1 family structure in China: a survival analysis based on life tables. Eur J Ageing. 2011;8:119. doi:10.1007/s10433-011-0189-1

8. Zhang Y, Goza FW. Who will care for the elderly in China?: a review of the problems caused by China's one-child policy and their potential solutions. J Aging Stud. 2006;20:151-164. doi:10.1016/j. jaging.2005.07.002

9. Fang EF, Scheibye-Knudsen M, Jahn HJ, et al. A research agenda for aging in China in the 21st century. Ageing Res Rev. 2015;24:197-205.

10. Chu L-W CI. Nursing homes in China. J Am Med Dir Assoc. 2008;9:237-243. doi:10.1016/j.jamda.2008.01.008

11. Hao Q, Wu S, Ying L, et al. Current dilemmas of nursing homes in Chengdu: a cross-sectional survey. $J$ Am Med Dir Assoc. 2012;13:406.e9-406.e12. doi:10.1016/j.jamda.2011.08.002

12. Ka L, Hao Z. Response to the challenges of aging society: evolution of the objective of China's pension service. Shandong Soc Sci. 2014;13:66-70.

13. Liu ZW, Yu Y, Fang L, Hu M, Zhou L, Xiao SY. Willingness to receive institutional and community-based eldercare among the rural elderly in China. PLoS One. 2019;14:e0225314.

14. Wang D, Zhang H, Ren H, Luo Y. Qualitative analyses of lived experience for residents in the elderly care departments at the community health service centres in Southwestern China. Health Soc Care Community. 2018;26:e164-e172. doi:10.1111/hsc.12490

15. Shao W, Xi W. Status and problems in the pension service for the aged - a case study of dalian city. $J$ Changchun Univ. 2012;22:773-777.

16. General Office of Chongqing Government. Notice from the general office of the Chongqing people's government on the implementation plan of the Qianbai project for community-based elderly care services in Chongqing. Available from: http://www.cq.gov.cn/zwgk/fdzdgknr/ lzyj/xzgfxwj/szfbgt_38656/202001/t20200115_4754262.html/. Accessed August 14, 2020.

17. Chongqing Bureau of Civil Affairs. Opinions from the Chongqing bureau of civil affairs and the Chongqing development and reform commission on promoting the construction of community-based elderly care centers. Available from: http://www.cq.gov.cn/zwgk/ fdzdgknr/lzyj/xzgfxwj/szfbm_38657/smzj_38698/202001/ t20200115_4752829.html/. Accessed January 25, 2020.
18. Lehnert T, Günther $\mathrm{OH}$, Hajek A, Riedel-Heller SG, König HH. Preferences for home- and community-based long-term care services in Germany: a discrete choice experiment. Eur $J$ Health Econ. 2018;19:1213-1223. doi:10.1007/s10198-018-0968-0

19. Kuzuya M, Masuda Y, Hirakawa Y, et al. Day care service use is associated with lower mortality in community-dwelling frail older people. J Am Geriatr Soc. 2006;54:1364-1371. doi:10.1111/j.15325415.2006.00860.x

20. Liu Z, Yu Y, Fang L, Hu M, Zhou L, Xiao S. Willingness to receive institutional and community-based eldercare among the rural elderly in China. PLoS One. 2019;14:e0225314. doi:10.1371/journal.pone.0225314

21. Makharadze T, Kitiashvili A, Bricout JC. Community-based day-care services for people with intellectual disabilities in Georgia: a step towards their social integration. J Intellect Disabil. 2010;14:289-301. doi:10.1177/1744629510393186

22. Kim HS, Suh Y, Kim MS, et al. Effects of community-based primary care management on patients with hypertension and diabetes. Asia Pac J Public Health. 2019;31:522-535. doi:10.1177/ 1010539519867797

23. Shen C, Wang N, Liu P, et al. Survey study on nursing needs of 120 disabled elderly people based on perspective of community home care. Chongqing Med. 2020;9:1520-1524.

24. Gu T, Li D, Li L. The elderly's demand for community-based care services and its determinants: a comparison of the elderly in the affordable housing community and commercial housing community of China. J Healthc Eng. 2020;1840543.

25. Chongqing People's Congress. Guidance on retrofitting elevators in existing residential buildings. Available from: http://www.ccpc.cq.cn/ home/index/more/u/jygk/id/216374.html. Accessed November 20, 2020.

26. Chongqing Bureau of Civil Affairs. Construction specifications for community-based elderly care facilities. Available from: http://mzj. cq.gov.cn/zwgk_218/fdzdgknr/dfbz/202006/t20200602_7531892. html. Accessed November 22, 2020.

27. Nicholl J, West J, Goodacre S, Turner J. The relationship between distance to hospital and patient mortality in emergencies: an observational study. Emerg Med J. 2007;24:665-668. doi:10.1136/ emj.2007.047654

28. Social Welfare Department. Code of practice for residential care homes (elderly persons). Available from: https://www.swd.gov.hk/ doc/LRB/LORCHE/CodeofPractice_E_201303_201503R5.pdf. Accessed November 22, 2020.

29. Government of New York. Standards of construction for health care facilities. Available from https://regs.health.ny.gov/sites/default/files/ pdf/recently_adopted_regulations/2010-12-29_standards_of_construc tion_for_health_care_facilities.pdf. Accessed November 22, 2020.

30. Zeng Y, Hu X, Li Y, et al. The quality of caregivers for the elderly in long-term care institutions in Zhejiang Province, China. Int J Environ Res Public Health. 2019;16:2164. doi:10.3390/ijerph16122164

31. Sloane PD, Zimmerman S, Chen X, et al. Effect of a person-centered mouth care intervention on care processes and outcomes in three nursing homes. J Am Geriatr Soc. 2013;61:1158-1163. doi:10.1111/ jgs. 12317

32. Japanese Nursing Association. Nursing for the older people in Japan. Available from: https://www.nurse.or.jp/jna/english/pdf/info-02.pdf. Accessed November 7, 2020.

33. Kohlbacher F, Rabe B. Leading the way into the future: the development of a (lead) market for care robotics in Japan. Int $J$ Technol Policy Manag. 2015;15:21-44. doi:10.1504/IJTPM.2015.067797

34. Feng Z, Glinskaya E, Chen H, et al. Long-term care system for older adults in China: policy landscape, challenges, and future prospects. Lancet. 2020;396:1362-1372. doi:10.1016/S0140-6736(20)32136-X 


\section{Publish your work in this journal}

Risk Management and Healthcare Policy is an international, peerreviewed, open access journal focusing on all aspects of public health, policy, and preventative measures to promote good health and improve morbidity and mortality in the population. The journal welcomes submitted papers covering original research, basic science, clinical \& epidemiological studies, reviews and evaluations, guidelines, expert opinion and commentary, case reports and extended reports. The manuscript management system is completely online and includes a very quick and fair peer-review system, which is all easy to use. Visit http://www.dovepress.com/testimonials.php to read real quotes from published authors. 